\title{
Amor y trabajo: Historias y memorias de una cooperativa y sus mujeres, Nicaragua 1983-2000
}

Autora: Turid Hagene

Comentario de Wendy Bellanger

\section{AMOR Y TRABAJO}

Historias y memorias de una cooperativa y sus mujeres, Nicaragua 1983-2000

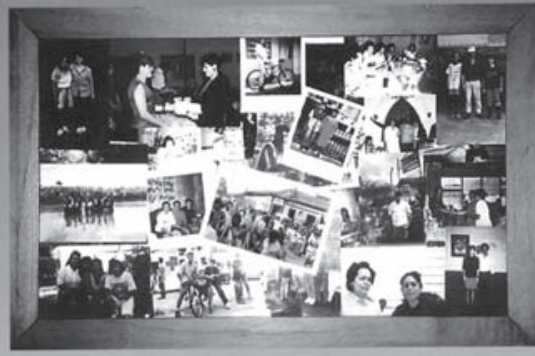

Turid Hagene
Este estudio, que retrata una cooperativa y sus mujeres, resulta sugerente y estimulante pues su autora no se conforma con describir la cooperativa y reflexionar sobre su funcionamiento o su inserción en el contexto político. No se dedica solamente a detallar la organización del trabajo, la producción o los pormenores de las transacciones económicas de la cooperativa. Turid Hagene asume el complejo y prolongado reto de explorar la construcción de significado en la vida de las cooperativistas y de escarbar a fondo en sus relaciones, su identidad y sus memorias.

Los objetivos que la investigadora se planteó distan mucho de los que usualmente encontramos en los estudios sociológicos que se realizan en este país. Éstos no actuaron como una camisa de fuerza para la investigadora. Por el contrario, dieron lugar a una metodología que exigió un contacto personal y prolongado entre Hagene y las cooperativistas, y estimuló la capacidad autoreflexiva de la investigadora. En consecuencia, el estudio contiene reflexiones y hallazgos innovadores

\section{Su propósito}

Como propósito de la investigación Hagene se planteó "aprender, entender y escribir sobre las mujeres, y no ayudarlas ni cambiarlas" porque reconoció que ella como 
investigadora no está en la posición de conocer mejor "el problema” de las mujeres que las mujeres mismas (p.48-49).

Llama la atención que en medio del fervor que suscita la lucha por el "empoderamiento" de las mujeres del tercer mundo, Hagene señala que a las mujeres de La Esperanza, ella no las ve faltas de poder (p.49). Gracias a esta postura, su investigación no acaba siendo secuestrada por objetivos que, al limitarse a buscar la solución de un problema, pasan por alto la complejidad de la vida de las personas, y lo difícil que es comprender sus relaciones y decisiones.

\section{Su metodología}

A diferencia de la mayoría de los estudios que se realizan en el país, Hagene no utiliza la encuesta como fuente única o primordial de información. En su estudio prevalece la observación participativa que realiza en sucesivas ocasiones a lo largo de un admirable -y envidiable- período de ocho años (en 1992, 1996, 1997, 1998 y 2000), incluye el análisis de una gran diversidad de fuentes escritas, numerosas entrevistas, relatos de vida y hasta un seminario con las cooperativistas.

Los relatos de vida son utilizados por Hagene por su ventaja de "mostrar las ambigüedades y contingencias inherentes a las decisiones tomadas"(p.259). Su enfoque se debe a que ella no va simplemente en busca de hechos. En efecto, gracias a la diversidad de técnicas empleadas, descubre "hechos" registrados en documentación oficial, que en realidad no ocurrieron.

\section{Su capacidad autoreflexiva}

Hagene no intenta retratarnos la verdad sino las verdades, "interpretaciones situadas de lo que ocurrió" (p.44). Acepta que su punto de vista está configurado por sus preconcepciones y opta por invitar al lector/a a ver o imaginar la perspectiva de las actoras/es involucrados. Hagene reconoce que los textos son producidos en conjunto por ella y sus entrevistadas (p.54), que ella seleccionó los relatos con los que trabajó, las partes que nos presenta, y que realizó una interpretación.

Además, la autora se pone ella misma bajo la lupa e incluye en su escrito una reflexión sobre su propia cultura, su propio contexto, y reconoce que su bagaje personal explica las impresiones que vivió en su trabajo de campo. Ella comprendió que para entender a las mujeres debía conectarse también con su propia vida (sus hallazgos están situados y dependen de su perspectiva) (p. 386-387).

Su reflexión también incluye una meditación sobre cómo las mujeres la percibían y cómo su estatus de extranjera influía en las cosas que estarían dispuestas a decir (p.55). Señala que contarle sus cosas a ella, "una mujer blanca, de clase media y de su misma edad o poco más, pudo haber condicionado la forma en que ellas reconstruyeron sus recuerdos y representaron sus vidas" (p.258). A la vez toma en cuenta que ella es de Noruega, el país de donde provenían los recursos con que la cooperativa contaba (p.258). 
La auto-reflexividad de Hagene le permite presentarnos un análisis más honesto, más justo con las mujeres, y además, libre de la ingenuidad que pesa sobre otros estudios. Salta a la vista cuánto se aleja de la epistemología instrumentalizadora, basada en el paradigma de sujeto y objeto. (Horkheimer y Adorno, 2004: 59-64).

En su estudio, Hagene se aparta de la instrumentalización del conocimiento que tiene al mercado como su gran legitimador (Horkheimer 2002) y que debe probar su valor demostrando su utilidad y aplicabilidad. Gracias a esto, ella logra pensar la situación de las mujeres sin caer, por ejemplo, en el discurso del empoderamiento, omnipresente en el mercado de las consultorías y proyectos de cooperación.

Hagene también va más allá del paradigma de la acción comunicativa, introducido por Habermas -que dice que el conocimiento lo produce el diálogo intersubjetivo- para incluir en su análisis la comunicación no verbal entre ella y las cooperativistas. La observación participante le da la oportunidad de ir más allá del diálogo. Hagene toma en cuenta el efecto de su identidad y sus sentidos en la investigación. Su perspectiva es la de quien acepta que nuestras reacciones a los estímulos las determina en gran medida nuestra identidad y su bagaje particular que incluye ideas sobre gustos, autoridad y posición social. Ella involucra sus sentidos en la experiencia y además, como sugiere Bourdieu, "[convierte] la reflexividad en una disposición constitutiva de [su] habitus científico" (Bourdieu 2003:155).

\section{Algunos hallazgos}

En este estudio -en el que no es la institución de la cooperativa la que ocupa el interés central del análisis, sino las cooperativistas viviendo en un mundo que va más allá de la cooperativa- puede apreciarse cómo las decisiones laborales tomadas por las mujeres son moldeadas por sus creencias religiosas, su vida emocional y los roles de género aceptados en su cultura. Queda claro que al tomar decisiones en su vida económica, las cooperativistas no se remiten simplemente a un cálculo de costo beneficio, como muchos estudios de economía suelen asumir.

Queda claramente reflejado que además de las relaciones laborales, aspectos personales como las relaciones sentimentales de las cooperativistas, estaban inevitablemente ligados a sus vidas profesionales en la cooperativa (p.169). Hagene descubre que en sus decisiones laborales muchas veces pesan más las razones emocionales que las materiales.

El concepto del patronazgo se convierte en la clave para comprender la percepción que tienen las cooperativistas del mundo que las rodea (p.216). Hagene describe cómo las mujeres entablan relaciones de patronazgo tanto en su práctica profesional como en su práctica religiosa, y al analizar la forma en que se vive el patronazgo en la práctica religiosa, logra comprender mejor las relaciones de patronazgo que se viven en la vida laboral. De esta manera, el lector/a logra percibir la complejidad del comportamiento y las relaciones entabladas por las mujeres en su vida laboral, que respondían al estilo de patrón percibido por ellas y la respuesta emocional que les provocaba. 


\section{Para concluir}

La riqueza y profundidad de este estudio lo convierten en una lectura necesaria para investigadores/as interesados en el tema de las cooperativas, las relaciones de género, la cultura política, la cultura religiosa, la Revolución Sandinista, la globalización y la cooperación para el desarrollo. Pero además es una lectura que recomendaría a docentes y estudiantes para reflexionar sobre metodología de la investigación en las ciencias sociales.

En la introducción de "Amor y trabajo", Turid Hagene expresa que "si hay alguna contribución que [ella] pueda hacer, [piensa] que ésta consiste en comprensión y respeto hacia los sujetos de [su] estudio y sus luchas, su inventiva y su gran sentido del humor”.

Y en efecto, al leer "Amor y trabajo", se llega a comprender y respetar a las cooperativistas, pero además, con su autora, se les llega a admirar.

\section{Referencias bibliográficas}

Bourdieu, P. (2003). El oficio de científico. Ciencia de la ciencia y reflexividad. Barcelona: Editorial Anagrama.

Horkheimer, M. (2002): Crítica de la razón instrumental. Madrid: Editorial Trotta.

Horkheimer, M. \& Adorno, T. W. (2004): Dialéctica de la ilustración. Madrid: Editorial Trotta. 